\title{
Composite Phymatoderma from Neogene deep-marine deposits in Japan: Implications for Phanerozoic benthic interactions between burrows and the trace-makers of Chondrites and Phycosiphon
}

\author{
Kentaro Izumi \\ Acta Palaeontologica Polonica 60 (4), 2015: 1009-1020 doi:http://dx.doi.org/10.4202/app.00060.2014
}

Among composite trace fossils, one of the most common structures throughout the Phanerozoic are structures (e.g., dwelling trace, feeding trace) reworked by Chondrites and/or Phycosiphon. However, differences in the nature of the reworking behaviors of these two ichnogenera remain unknown. Thus, in this study, composite Phymatoderma specimens from the Neogene deep-marine Shiramazu Formation in Japan, particularly those reworked by Chondrites and Phycosiphon, were analyzed to reveal the specific conditions that might control the activities of these trace-makers. Phymatoderma reworked by Phycosiphon is significantly larger than non-reworked Phymatoderma, whereas Phymatoderma reworked by Chondrites shows no significant difference in burrow diameter compared with non-reworked Phymatoderma . The recognized size selectivity (i.e., preference for larger burrows) by the Phycosiphon trace-maker can be explained by considering the different feeding strategies of these two ichnogenera; namely deposit-feeding Phycosiphon-makers, which must have processed a significant mass of sediment to obtain sufficient organic matter, whereas chemosymbiotic Chondrites-producers did not require a lot of sediment to obtain nutrients. In order to test these interpretations, a dataset of Phanerozoic trace fossils reworked by Chondrites/Phycosiphon were compiled. Consequently, the Phycosiphon-producers' preference toward relatively larger burrows was recognized, quantitatively supporting the results of this study. The compilation also indicates that the burrow size might have become one of the important limiting factors for the Phycosiphon-producers that tried to rework the sediments within previous subsurface burrows, at least for 80 million years.

Key words: Phymatoderma, Phycosiphon, Chondrites, burrows, size, benthic interactions, Phanerozoic, Neogene, Japan.

Kentaro Izumi [izumi.kentaro@nies.go.jp], Department of Earth and Planetary Science, University of Tokyo, 7-3-1 Hongo, Bukyo-ku, Tokyo 113-0033, Japan; current address: Center for Environmental Biology and Ecosystem Studies, National Institute for Environmental Studies, 16-2 Onogawa, Tsukuba, 
Ibaraki 305-8506, Japan.

This is an open-access article distributed under the terms of the Creative Commons Attribution License (for details please see creativecommons.org), which permits unrestricted use, distribution, and reproduction in any medium, provided the original author and source are credited.

\footnotetext{
FoF

FoF Supplementary file $(211.7 \mathrm{kB})$
} 